\title{
A Xenograft Model for Venous Malformation
}

\author{
Jillian Goines, \\ Division of Experimental Hematology and Cancer Biology, Cincinnati Children's Hospital Medical \\ Center, Cincinnati, OH, USA \\ Elisa Boscolo \\ Division of Experimental Hematology and Cancer Biology, Cincinnati Children's Hospital Medical \\ Center, Cincinnati, OH, USA; Department of Pediatrics, University of Cincinnati College of \\ Medicine, Cincinnati, $\mathrm{OH}$, USA
}

\begin{abstract}
Xenograft models allow for an in vivo approach to monitor cellular functions within the context of a host microenvironment. Here we describe a protocol to generate a xenograft model of venous malformation (VM) based on the use of human umbilical vein endothelial cells (HUVEC) expressing a constitutive active form of the endothelial tyrosine kinase receptor TEK (TIE2 p.L914F) or patient-derived EC containing TIE2 and/or PIK3CA gene mutations. Hyperactive somatic TIE2 and PIK3CA mutations are a common hallmark of VM in patient lesions. The EC are injected subcutaneously on the back of athymic nude mice to generate ectatic vascular channels and recapitulate histopathological features of VM patient tissue histology. Lesion plugs with TIE2/PIK3CA-mutant EC are visibly vascularized within 7-9 days of subcutaneous injection, making this a great tool to study venous malformation.
\end{abstract}

\section{Keywords}

Venous malformation; Xenograft model; Endothelial cells; TIE2

\section{Introduction}

The establishment of the vasculature includes two main processes termed vasculogenesis and angiogenesis. Vasculogenesis is the "de novo" formation of blood vessels from precursor cells, while angiogenesis entails the subsequent sprouting from the preexisting vessels [1]. Defects during the angiogenic process can lead to vascular anomalies such as venous malformation $(\mathrm{VM})$ which is characterized by the development of greatly dilated, ectatic veins [2-4].

Normal and pathological angiogenesis encompasses several critical cellular functions such as endothelial cell adhesion, extracellular matrix (ECM) remodeling, proliferation,

Corresponding Author elisa.boscolo@cchmc.org.

14.We encourage staining of UEA-1 or a human endothelial-specific antibody, such as antiplatelet endothelial cell adhesion molecule (PECAM1 or CD31), to ensure proper xenograft analysis of channels are made by the injected human EC versus mouse EC. 
migration, and lumen formation [5]. While in vitro 2D cultures of endothelial cells (EC) provide a platform to investigate each of these cellular properties, the combined interplay of EC functions can be best assessed in an in vivo setting. In vivo models of vascular anomalies are based on 1-transgenic animals expressing the genetic defect identified in patients and on 2-xenografts consisting of transplantation or injection of human patient tissue or cells. In the vascular anomaly field, transgenic mouse models are primarily based on dominant negative [6] or constitutively active genetic mutations [7-11]. Transgenic mouse models of VM are based on the ubiquitous (CAG-CreERT2), epithelial/endothelial (Sprr2f+), or embryonic mesoderm-restricted expression of the human PIK3CA p. H1047R [7, 8]. While a transgenic murine model of VM based on TIE2 mutations has not been reported, expression of TIE2 p. R849W in zebrafish resulted in formation of vascular lesions resembling human VM lesions [12]. Transgenic models are great tools for investigating the whole body or tissue-specific effects of different genetic mutations or gene loss of function; however, this can result in widespread pathological vasculature and early lethality. Current transgenic models fail to take into account the sporadic nature of the mutational events found in patient tissue, and may not exactly recapitulate the effects that result in localized vascular lesions. Conversely, xenograft models allow for the use of patient-derived tissue or cells to generate patient-specific platforms some of which are widely used in the cancer field to test drug treatments for precision medicine.

Xenografts are based on the use of immunocompromised mice that do not reject human cells. Commonly used mouse strains are: athymic nude (nu/nu) mice, severely compromised immunodeficient (SCID; Prkdc ${ }^{\text {scid }}$ ) mice, and recombination-activating gene 2 (Rag2)knockout mice. To develop a mouse model with a human immune system, humanized mice can be generated by the administration in NSG (NOD scid gamma mouse) mice of human immune cells before implantation of the xenograft [13].

Patient-derived xenografts (PDX) based on tissue or organoid transplantation are widely used to study tumor propagation and to determine drug dosing, treatment schedules, and routes of administration that maximize antitumor efficacy and therapeutic window [14]. Subcutaneous inoculation of different cell types is also used to generate xenografts for the study of tumor growth, metastasis, and vascular anomalies or for regenerative medicine. The advantages of this method are the direct access for implantation and ease of monitoring the tumor/lesion growth. Furthermore, a recent study showed that injection of unassembled vascular cells (i.e., cell suspension) allows for anastomosis with the host vasculature and subsequent perfusion while preassembled vascular networks do not engraft efficiently [15]. In most cases, single cell suspension of normal EC such as human umbilical vein endothelial cells (HUVEC) or cord blood endothelial colony-forming cells (cbECFC) requires a support cell type such smooth muscle cells or bone marrow mesenchymal progenitor cells (bmMPC) to assemble into blood vessels and anastomose with the host vascular network [16, 17]. Here we describe a protocol in which EC isolated from lesions in VM patients and expressing a mutated constitutive active form of TIE2 or PIK3CA can undergo significant morphogenesis and generate perfused pathological ectatic vessels even when injected alone [18-20].

To promote EC morphogenesis in the xenograft, injected vascular cells are mixed with an ECM component solution such as Fibronectin and Collagen, or a mixture of ECM and 
growth factors such as Matrigel (matrix preparation enriched in collagen IV, nidogen and laminin that is derived from the mouse Engelbreth-Holm-Swarm sarcoma) or the peptide hydrogel PuraMatrix ${ }^{\circledR}[21,22]$.

In this protocol, we present methods for establishing a patient-derived xenograft in mice based on injection of EC isolated from VM lesions in patients or HUVEC expressing TIE2 p.L914F, the most frequent mutation found in individuals affected by VM (Fig. 1).

\section{Materials}

All buffers and solutions are prepared at room temperature (RT) and stored at $4{ }^{\circ} \mathrm{C}$ (unless indicated otherwise). Consumable equipment, such as pipette tips, needles, syringes, and microtubes should be sterilized prior to use. All reagents are prepared in a clean biosafety cabinet and waste disposed of according to biohazardous waste disposal regulations.

\subsection{Cell Culture}

1. Endothelial cells (EC): HUVEC-TIE2-L914F and patient-derived EC (CD31+) (see Note 1).

2. Endothelial growth medium (10\% FBS/EGM-2): Endothelial Cell Growth Medium-2 (EGM ${ }^{\mathrm{TM}}-2$ ), Fetal Bovine Serum (FBS): Remove $50 \mathrm{~mL}$ of endothelial basal medium (EBM-2) from bottle and add $50 \mathrm{~mL}$ of FBS. Thaw (see Note 2) and add SingleQuots ${ }^{\mathrm{TM}}$ growth factor supplement to bottle, except for hydrocortisone. Add $5 \mathrm{~mL}$ of $100 \times$ penicillin-streptomycin-L-glutamine. Gently mix and sterile-filter through a $0.2 \mu \mathrm{m}$ pore-sized bottle filter into an autoclaved Wheaton bottle. Store at $4{ }^{\circ} \mathrm{C}$ (or $-20^{\circ} \mathrm{C}$ ) in $50 \mathrm{~mL}$ conical tube aliquots ( see Note 3).

3. Sodium carbonate coating buffer $\left(\mathrm{Na}_{2} \mathrm{CO}_{3} 0.1 \mathrm{M} \mathrm{pH} 9.4\right)$ : Weigh $5.3 \mathrm{~g}$ of sodium carbonate in $500 \mathrm{~mL}$ of deionized water. Adjust $\mathrm{pH}$ to 9.4 and filter through a $0.2 \mu \mathrm{m}$ bottle top filter into an autoclaved Wheaton bottle. Store at RT.

4. Human plasma fibronectin purified protein.

5. PBS: Sterile $1 \times$ phosphate buffered solution.

6. $15 / 50 \mathrm{~mL}$ conical tubes.

7. $100 \times 20 \mathrm{~mm}$ tissue culture-treated plates.

8. $145 \times 20 \mathrm{~mm}$ tissue culture-treated plates.

9. Trypsin solution: $0.05 \%$ trypsin $-0.5 \mu \mathrm{M}$ EDTA.

10. Trypan Blue Solution, $0.4 \%$.

\footnotetext{
1. Previous publications from our lab have demonstrated that our in vivo model can recapitulate perfused, ectatic VM channel formation using both transfected HUVEC with a TIE2-L914F mutation as well as patient-derived EC [18-20]. Please refer to [19] on how to isolate and generate endothelial cell populations from patient tissue and identify TIE2 or PIK3CA hot-spot mutations.

2. SingleQuots ${ }^{\mathrm{TM}}$ must be thawed slowly. Thawing can occur after $30 \mathrm{~min}$ at room temperature or up to $2 \mathrm{~h}$ at $4{ }^{\circ} \mathrm{C}$. Thawing at higher temperatures is not recommended as it will affect the stability of growth factors.

${ }^{3}$. GMM $^{\mathrm{TM}}$-2 Endothelial Cell Growth Medium-2: $50 \mathrm{~mL}$ aliquots can be stored at $4{ }^{\circ} \mathrm{C}$ up to 2 weeks or $-20{ }^{\circ} \mathrm{C}$ for up to 1 year immediately following preparation.
} 
11. Hausser Scientific Bright-Line ${ }^{\mathrm{TM}}$ Counting Chambers.

\subsection{Subcutaneous Injection of Cells into Mouse}

1. Mice, 5-6 week old Hsd:Athymic Nude Foxn $1^{\text {nu }}$.

2. Needles, $26 \mathrm{G} \times 5 / 8$ in. Sub-Q sterile needles.

3. Syringes, $1 \mathrm{~mL}$ with Luer Lock.

4. Matrigel: Corning ${ }^{\mathrm{TM}}$ Matrigel ${ }^{\circledR}$ Basement Membrane Matrix (Phenol Red-Free).

5. Ice bucket filled with ice.

6. Aluminum foil.

7. Isoflurane.

8. Anesthesia machine with nose cone attachment.

9. Ear punch.

\subsection{Lesion Plug Measurements and Collection}

1. Caliper.

2. Scale to weight mice.

3. Dissection tools, including scissors and forceps.

4. Cutting board.

5. Seventy percent ethanol $(\mathrm{EtOH})$ in deionized water.

6. Camera stage with camera.

7. Ruler.

8. $10 \%$ formalin buffered solution.

\subsection{Tissue Staining}

1. Positive-charged glass slides.

2. Staining slide holder and containers.

3. Xylene.

4. Ethanol $(100 \%, 90 \%, 80 \%, 70 \%)$ in deionized water.

5. Hematoxylin (Gill's Formula).

6. $\quad$ Eosin Y (alcohol-based).

7. Antigen retrieval solution: Tris-EDTA, $\mathrm{pH}$ 9.0. Weigh $0.6 \mathrm{~g}$ of Trizma base and $1 \mathrm{~mL}$ of $0.5 \mathrm{M}$ EDTA to $500 \mathrm{~mL}$ of deionized water. Adjust $\mathrm{pH}$ to 9.0. Add 250 $\mu \mathrm{L}$ of Tween 20. Store at room temperature (RT).

8. Humidifying slide chamber.

9. Liquid-repellent Super PAP pen. 
10. Blocking buffer: 5\% normal horse serum in PBS.

11. Biotinylated Ulex europaeus agglutinin-1 (UEA-1).

12. $3 \%$ hydrogen peroxide solution: To prepare, add $1 \mathrm{~mL}$ of $30 \%$ hydrogen peroxide to $9 \mathrm{~mL}$ of deionized water.

13. Streptavidin horseradish peroxidase (HRP)-conjugated Antibody.

14. DAB: $3,3^{\prime}$ Diaminobenzidine Reagent. Peroxidase Substrate Kit. Prepare according to the manufacturer's recommendations.

15. Permount Mounting Medium.

16. Coverslips.

17. Brightfield microscope with $20 \times$ objective for imaging.

18. ImageJ Software.

\section{Methods}

Carry out procedures in a biosafety cabinet, unless otherwise specified. All procedures must be approved under IBC Biosafety Level 2 regulations and protocol. All mouse procedures must be performed under an approved IACUC protocol and regulations observed. This protocol should be completed as quickly and efficiently as possible to minimize cell exposure to stress.

\subsection{Cell Plating and Expansion}

It is important to culture and expand more EC than what is needed for the injection. It is recommended by our laboratory to count cells during passaging step to ensure cells are growing and to properly plan out when to schedule your injection. Here we will describe how to thaw, passage, and maintain EC culture to prepare for in vivo injection of the cells.

1. Plates will need to be ECM-coated to ensure proper cell adhesion. Pipet $5 \mathrm{~mL}$ of sodium carbonate coating buffer per $100 \times 20 \mathrm{~mm}$ tissue culture-treated plate. Add $1 \mu \mathrm{g} / \mathrm{cm}^{2}$ of human plasma fibronectin purified protein and gently distribute the liquid onto plate.

2. Incubate plate at $37^{\circ} \mathrm{C}, 5 \% \mathrm{CO}_{2}$ for $20 \mathrm{~min}$.

3. Aspirate and wash plate with PBS prior to culturing cells.

4. Quickly and completely thaw a cryovial of cells in a $37{ }^{\circ} \mathrm{C}$ water bath. Transfer into a new $15 \mathrm{~mL}$ conical tube with $1 \mathrm{~mL}$ of endothelial growth medium and pellet cells by centrifugation for $5 \mathrm{~min}$ at 400 relative centrifugal force (rcf), RT.

5. Resuspend cell pellet into $10 \mathrm{~mL}$ of endothelial growth medium and seed cells into a $100 \times 20 \mathrm{~mm}$ tissue culture-treated plate. Change medium every $48 \mathrm{~h}$ while cells are recovering.

6. Once cells reach $80-90 \%$ confluency, passage cells by seeding $1-1.5 \times 10^{4}$ cells $/ \mathrm{cm}^{2}$ into $145 \times 20 \mathrm{~mm}$ tissue culture-treated and fibronectin-coated plates. 
Add up to a total of $25 \mathrm{~mL}$ of endothelial growth medium per plate (see Note 4). Continue to passage cells until desired cell number has been met. Do not passage cells the day before injection.

\subsection{Day Before Injection}

1. Prechill syringes, needles, and pipette tips in $-20{ }^{\circ} \mathrm{C}$ freezer overnight.

2. Slowly thaw Matrigel as per manufacturer instructions. Briefly, thaw a $10 \mathrm{~mL}$ bottle immersed on ice and place ice bucket at $4{ }^{\circ} \mathrm{C}$ overnight. Aliquot excess Matrigel ${ }^{\circledR}$ into $1.5 \mathrm{~mL}$ microtubes to avoid freeze-thaw cycles.

\subsection{Endothelial Cell Preparation and Counting}

1. Trypsinize cells using $5 \mathrm{~mL}$ of prewarmed trypsin solution per $145 \times 20 \mathrm{~mm}$ tissue culture-treated plate. Incubate at $37{ }^{\circ} \mathrm{C}, 5 \% \mathrm{CO}_{2}$, for 2 min to allow detaching of all cells from plate surface.

2. Neutralize trypsin with $5 \mathrm{~mL}$ of endothelial growth medium for every $5 \mathrm{~mL}$ of trypsin, transfer to $15 \mathrm{~mL}$ conical tube, and pellet cells by centrifugation for 5 min at $400 \mathrm{rcf}$, RT. Resuspend cells in $10 \mathrm{~mL}$ of medium.

3. Mix $20 \mu \mathrm{L}$ of cells with $20 \mu \mathrm{L}$ of trypan blue for cell counting using Hausser Counting Chamber [23].

4. Determine the volume needed to obtain $2.5 \times 10^{6}$ cells per injection (see Note 5).

5. Transfer this volume into a new $15 / 50 \mathrm{~mL}$ conical tube and pellet cells by centrifugation for $5 \mathrm{~min}$ at $400 \mathrm{rcf}$, RT.

6. Aspirate the supernatant, not disturbing the cell pellet (see Note 6). Chill on ice until ready to resuspend in Matrigel ${ }^{\circledR}$.

\subsection{Syringe Preparation}

1. Prepare syringes with needles over ice to prevent solidification of Matrigel ${ }^{\circledR}$.

2. Dislodge cell pellet by gently tapping the $15 \mathrm{~mL}$ conical tube. Resuspend the cell pellet with $200 \mu \mathrm{L}$ of Matrigel ${ }^{\circledR}$ per injection on ice (see Note 7).

3. Using $1 \mathrm{~mL}$ pipette and $1 \mathrm{~mL}$ syringes, simultaneously pipet Matrigel-cell mixture into syringe opening by suction force while pulling plunger of syringe. Luer lock a $26 \mathrm{G} \times 5 / 8$ in. sterile needle to the syringe and keep prepared syringes flat on ice prior to injection.

\footnotetext{
4.Expansion of cells is based on cell number for optimal seeding and cell proliferation. EC that are growing well may require passaging every $48-72 \mathrm{~h}$. Continue to passage cells on $145 \times 20 \mathrm{~mm}$ plates until ready to be injected.

5 . Any cells left over that will not be used for injection can be cultured at a density of $1-2 \times 10^{4} \mathrm{cells} / \mathrm{cm}^{2}$ on a coated $100 \times 20 \mathrm{~mm}$ or $145 \times 20 \mathrm{~mm}$ tissue culture-treated plate to reduce the amount of time cells are left out of incubator in case storage of cells is necessary for use later.

6. We leave a small quantity of medium (about 50-70 $\mu \mathrm{L}$ ) with pellet to break up cells prior to resuspension in Matrigel. This helps with the viscosity of the Matrigel to create a more homogeneous solution of cells for injections.

7. Suspension of cells in Matrigel must be performed on ice to prevent from solidifying. Avoid creating bubbles while resuspending.

Pipet thoroughly to prevent clumps of cells and to obtain a homogenous cell suspension.
} 


\subsection{Subcutaneous Injection into Mouse}

1. Prepare anesthesia machine of choice, according to the manufacturer's protocol, and attach nose cone (see Note 8). Ensure mice are properly anesthetized before subcutaneous injection.

2. Gently roll prepared syringe with needle to reincorporate any settled cells and flick bubbles to the needle end of syringe. Uncap needle and push plunger to distribute mixture through the needle.

3. Pinch and create "tentlike" structure on right back side of mouse hind leg and insert needle subcutaneously right under the skin (see Note 9). Holding needle at $45^{\circ}$ angle carefully inject $200 \mu \mathrm{L}$ of the cell-Matrigel ${ }^{\circledR}$ mixture to create a small spherical mass (Fig. 2). This procedure can be repeated on the left back side of mouse hind leg. Discard needle and syringe into appropriate Category 1 sharp container.

4. Record mouse weight using a scale (see Note 10), ear tag the mouse, and return to cage. Monitor mouse to ensure it returns to normal activity.

\subsection{Lesion Growth Monitoring}

1. Using a caliper, record lesion area by measuring the length of the long and short sides of the plug as shown in Fig. 3. Note lesion size, color, and any abnormal affects such as bleeding, bruising, or discoloration from previous color record.

2. Measurements are read every other day up until collection day (see Note 11).

\subsection{Tissue Collection and Processing}

1. Prior to lesion tissue collection, euthanize mice by $\mathrm{CO}_{2}$ per IACUC protocol.

2. Spray lesion tissue area with $70 \% \mathrm{EtOH}$ and carefully dissect plug from hind legs with the use of scissors. Leave skin on plug to prevent altering the lesion mass.

3. Set up a camera stage with a camera. Align plugs onto a cutting board aside a ruler. Take an image of plugs to record gross vascularity of lesions.

4. Fix tissue by placing the lesion plug in $10 \%$ formalin overnight at RT. The next day, replace fixative with PBS.

5. Process tissue for paraffin embedding (see Note 12).

\footnotetext{
8. Once mouse is anesthetized, use nose cone attachment to ensure mouse is properly anesthetized throughout the injection procedure. Anesthesia machine method is preferred to use as little anesthesia as possible and monitor mouse activity quickly following subcutaneous injection. In our laboratory, we use the EZ-Anesthesia Classic System with oxygen flowmeter rate between 1 and 3 and isoflurane vaporizer concentration level between 2 and 3 for our mice.

${ }^{9}$ Ensure that needle is only skin deep by releasing pinched skin. Avoid poking the hind leg muscle to prevent injection of plug into muscle. It is our goal to study vessel development that occurs within the Matrigel plug with minimal assistance infiltration from mouse endothelium.

10. As per our IACUC protocol, we record mouse weight to ensure that our lesion size does not become a burden to the mouse health as the lesion grows over time.

11. Growing rate of lesions may depend on the type and number of EC injected. Xenograft lesions size at Day 1 is about $80-100 \mathrm{~mm}^{2}$. In the case for venous malformation EC, 9 days is a sufficient amount of time to visualize enlarged vascular channels of human origin in the center of the plug, with minimal assistance from mouse endothelium typically measuring up to $150-200 \mathrm{~mm}^{2}$.
} 


\subsection{Staining of Lesion Sections}

We stain the lesions for Hematoxylin and Eosin (H\&E, see Subheading 3.8.1) to detect vascular structures of lesions. We further stain lesions with a human endothelial-specific lectin marker Ulex europaeus agglutinin-1 (UEA-1, see Subheading 3.8.2) to confirm that vascular structures are formed by human-derived EC.

1. Prepare tissue slides by cutting $5 \mu \mathrm{m}$ paraffin tissue sections (see Note 13).

2. Melt wax at $60{ }^{\circ} \mathrm{C}$ for $1 \mathrm{~h}$ prior to staining.

3. Fumes from xylene and $\mathrm{EtOH}$ are toxic. Ensure that entire staining procedure is performed in a well-ventilated area and chemical fume flow hood to minimize fume exposure. De-paraffinize and rehydrate tissue by sequentially incubating slide in xylene for $10 \mathrm{~min}, 100 \% \mathrm{EtOH}$ for $5 \mathrm{~min}, 90 \% \mathrm{EtOH}$ for $3 \mathrm{~min}$, and $80 \% \mathrm{EtOH}$ for $3 \mathrm{~min}$. Rinse slide in deionized water for $5 \mathrm{~min}$.

\subsubsection{Hematoxylin and Eosin (H\&E)}

1. Incubate sections in hematoxylin for $2 \mathrm{~min}$. Using a beaker and slide holder, rinse in a sink by a steady stream of tap water until water is clear.

2. Dehydrate slides by incubating tissue sequentially in $70 \% \mathrm{EtOH}$ for $1 \mathrm{~min}, 80 \%$ min, 90\% EtOH for $1 \mathrm{~min}, 100 \% \mathrm{EtOH}$ for $1 \mathrm{~min}$, and another fresh 100\% EtOH for $1 \mathrm{~min}$.

3. Stain sections in Eosin $\mathrm{Y}$ for $30 \mathrm{~s}$. Immediately following, rinse in $100 \% \mathrm{EtOH}$. Rinse in fresh $100 \%$ EtOH until solution is clear.

4. Incubate slide in xylene for $2 \mathrm{~min}$. Let slides dry for 5-10 min under the fume hood.

5. Pipet a drop of Permount Mounting medium per lesion section. At $45^{\circ}$ angle, lower coverslip to evenly distribute mounting medium and avoid bubble production under coverslip. Allow slides to dry overnight before imaging.

\subsubsection{Ulex europaeus Agglutinin-1 (UEA-1) Immunohistochemistry (IHC)}

1. Incubate tissue slide in a beaker with antigen retrieval solution, stirring on a heating block, for $20 \mathrm{~min}$ at $95^{\circ} \mathrm{C}$.

2. Remove beaker from heating block, allow solution to cool to $35^{\circ} \mathrm{C}$, then wash in PBS for 3 min.

3. Using a liquid-repellent Super PAP pen, draw a small circle around tissue section to be stained.

4. Incubate slide sections in blocking buffer for $30 \mathrm{~min}, \mathrm{RT}$.

\footnotetext{
12.We use the Pathology Core at Cincinnati Children's Hospital Medical Center to process our tissue for paraffin blocks.

13. To analyze vasculature inside of lesion plug, we cut $5 \mu \mathrm{m}$-thick sections sequentially. It is recommended that initial hematoxylin and eosin staining analysis begins $100 \mu \mathrm{m}$ into the tissue (about 1/3 of the xenograft plug). Moving toward the middle of the lesion is optimal to ensure vessels are formed by the human-derived endothelium rather than the mouse endothelium.
} 
5. Prepare a UEA-1 working solution by diluting $20 \mu \mathrm{g} / \mathrm{mL}$ of Biotinylated UEA-1 in blocking buffer. Pipet 50-100 $\mu \mathrm{L}$ of UEA-1 working solution per section and incubate for $1 \mathrm{~h}$ at RT in a humidifying chamber.

6. Wash slides two times in PBS for 3 min each.

7. Peroxidase quench slide sections in $3 \%$ hydrogen peroxide for $5 \mathrm{~min}, \mathrm{RT}$.

8. Wash slides two times in PBS for 3 min each.

9. Prepare $5 \mu \mathrm{g} / \mathrm{mL}$ of Streptavidin HRP-conjugated in blocking buffer. Pipet 50$100 \mu \mathrm{L}$ per section and incubate for $1 \mathrm{~h}$ at RT in a humidifying chamber.

10. Wash slides two times in PBS for 3 min each.

11. Prepare DAB solution and add $50-100 \mu \mathrm{L}$ per section. Incubate sections for 10 15 min, checking and monitoring for development of stain every 2-5 min.

Following staining, wash in PBS three times for 3 min each.

12. Incubate sections in hematoxylin for $3 \mathrm{~min}$. Using a beaker and slide holder, rinse in a sink by a steady stream of tap water until water is clear.

13. Sequentially incubate slide in $80 \% \mathrm{EtOH}$ for $1 \mathrm{~min}, 90 \% \mathrm{EtOH}$ for $1 \mathrm{~min}, 100 \%$ EtOH for $1 \mathrm{~min}$, and xylene for $2 \mathrm{~min}$. Let slides dry for 5-10 min under the fume hood.

14. Pipet a drop of Permount Mounting medium per section at $45^{\circ}$ angle, lower coverslip to evenly distribute mounting medium and avoid bubble production under coverslip. Allow slides to dry overnight before imaging.

\subsection{Vascular Channel Analysis}

A comprehensive and thorough analysis is performed to better understand the vascular channel formation of these xenograft lesions or eventual response to drug treatments. Vascular channels of lesions are quantified by measuring vascular area and vascular density.

1. Four to five images are taken per lesion section with a brightfield microscope at $20 \times$ magnification. Each photo is taken in an $x$-plane pattern within the lesion section to avoid overlap. Take at least one image with a scale bar for pixel-tomillimeter ratio calibration.

2. Images are loaded and stacked on ImageJ per lesion section. Using ImageJ, calibrate the pixels of your scale bar to convert measurements to millimeters by using "Set scale ..." under Analyze tab. This allows software to quantify relative vascular area for one single lesion.

3. A vascular channel is defined as any area that is lined with EC that may contain blood or fluid inside (Fig. 4). Using Freehand selections tool, manually outline vascular channels per image and add to ROI Manager on ImageJ. Do this for all channels on every image in stack.

4. Once all channels are outlined and entered into ROI manage, click on

"Measure." Using "Area" measurement, average the total area of the lesion over 
the total area of a single image. This will give you the average vascular area per total area for each lesion. Vascular density is measured by manually counting the number of vascular channels per section over the image/field area.

\section{Acknowledgments}

Research reported in this chapter was supported by the National Heart, Lung, and Blood Institute, under Award Number R01 HL117952 (E.B.), part of the National Institutes of Health. The content is solely the responsibility of the authors and does not necessarily represent the official views of the National Institutes of Health.

\section{References}

1. Folkman J, D'Amore PA (1996) Blood vessel formation: what is its molecular basis? Cell 87 (7)1153-1155 [PubMed: 8980221]

2. Brouillard P, Vikkula M (2007) Genetic causes of vascular malformations. Hum Mol Genet 16 Spec No. 2:R140-R149. 10.1093/hmg/ddm211 [PubMed: 17670762]

3. Dompmartin A, Vikkula M, Boon LM (2010) Venous malformation: update on aetiopathogenesis, diagnosis and management. Phlebology 25(5):224-235. 10.1258/phleb.2009.009041 [PubMed: 20870869]

4. Vikkula M, Boon LM, Carraway KL 3rd, Calvert JT, Diamonti AJ, Goumnerov B, Pasyk KA, Marchuk DA, Warman ML, Cantley LC, Mulliken JB, Olsen BR (1996) Vascular dysmorphogenesis caused by an activating mutation in the receptor tyrosine kinase TIE2. Cell 87(7):1181-1190. S0092-8674(00)81814-0 [pii] [PubMed: 8980225]

5. Stratman AN, Saunders WB, Sacharidou A, Koh W, Fisher KE, Zawieja DC, Davis MJ, Davis GE (2009) Endothelial cell lumen and vascular guidance tunnel formation requires MT1-MMPdependent proteolysis in 3-dimensional collagen matrices. Blood 114 (2):237-247. 10.1182/ blood-2008-12-196451 [PubMed: 19339693]

6. Crist AM, Lee AR, Patel NR, Westhoff DE, Meadows SM (2018) Vascular deficiency of Smad4 causes arteriovenous malformations: a mouse model of Hereditary Hemorrhagic Telangiectasia. Angiogenesis 21(2):363-380. 10.1007/s10456-018-9602-0 [PubMed: 29460088]

7. Castel P, Carmona FJ, Grego-Bessa J, Berger MF, Viale A, Anderson KV, Bague S, Scaltriti M, Antonescu CR, Baselga E, Baselga J (2016) Somatic PIK3CA mutations as a driver of sporadic venous malformations. Sci Transl Med 8(332):332ra342 10.1126/scitranslmed.aaf1164

8. Castillo SD, Tzouanacou E, Zaw-Thin M, Berenjeno IM, Parker VE, Chivite I, Mila-Guasch M, Pearce W, Solomon I, Angulo-Urarte A, Figueiredo AM, Dewhurst RE, Knox RG, Clark GR, Scudamore CL, Badar A, Kalber TL, Foster J, Stuckey DJ, David AL, Phillips WA, Lythgoe MF, Wilson V, Semple RK, Sebire NJ, Kinsler VA, Graupera M, Vanhaesebroeck B (2016) Somatic activating mutations in Pik3ca cause sporadic venous malformations in mice and humans. Sci Transl Med 8(332):332ra343 10.1126/scitranslmed.aad9982

9. di Blasio L, Puliafito A, Gagliardi PA, Comunanza V, Somale D, Chiaverina G, Bussolino F, Primo L (2018) PI3K/mTOR inhibition promotes the regression of experimental vascular malformations driven by PIK3CA-activating mutations. Cell Death Dis 9(2):45 10.1038/s41419-017-0064-x [PubMed: 29352118]

10. Rodriguez-Laguna L, Agra N, Ibanez K, Oliva-Molina G, Gordo G, Khurana N, Hominick D, Beato M, Colmenero I, Herranz G, Torres Canizalez JM, Rodriguez Pena R, Vallespin E, MartinArenas R, Del Pozo A, Villaverde C, Bustamante A, Ayuso C, Lapunzina P, Lopez-Gutierrez JC, Dellinger MT, Martinez-Glez V (2019) Somatic activating mutations in PIK3CA cause generalized lymphatic anomaly. J Exp Med 216(2):407-418. 10.1084/jem.20181353 [PubMed: 30591517]

11. Venot Q, Blanc T, Rabia SH, Berteloot L, Ladraa S, Duong JP, Blanc E, Johnson SC, Hoguin C, Boccara O, Sarnacki S, Boddaert N, Pannier S, Martinez F, Magassa S, Yamaguchi J, Knebelmann B, Merville P, Grenier N, Joly D, Cormier-Daire- V, Michot C, Bole-Feysot C, Picard A, Soupre V, Lyonnet S, Sadoine J, Slimani L, Chaussain C, Laroche-Raynaud C, Guibaud L, Broissand C, Amiel J, Legendre C, Terzi F, Canaud G (2018) Targeted therapy in patients with PIK3CA-related 
overgrowth syndrome. Nature 558 (7711):540-546. 10.1038/s41586-018-0217-9 [PubMed: 29899452]

12. Du Z, Ma HL, Zhang ZY, Zheng JW, Wang YA (2018) Transgenic expression of A venous malformation related mutation, TIE2-R849W, significantly induces multiple malformations of zebrafish. Int J Med Sci 15(4):385-394. 10.7150/ijms.23054 [PubMed: 29511374]

13. Okada S, Vaeteewoottacharn K, Kariya R (2019) Application of highly immunocompromised mice for the establishment of patient-derived xenograft (PDX) models. Cells 8(8). 10.3390/ cells8080889

14. Byrne AT, Alferez DG, Amant F, Annibali D, Arribas J, Biankin AV, Bruna A, Budinska E, Caldas C, Chang DK, Clarke RB, Clevers H, Coukos G, Dangles-Marie V, Eckhardt SG, Gonzalez-Suarez E, Hermans E, Hidalgo M, Jarzabek MA, de Jong S, Jonkers J, Kemper K, Lanfrancone L, Maelandsmo GM, Marangoni E, Marine JC, Medico E, Norum JH, Palmer HG, Peeper DS, Pelicci PG, Piris-Gimenez A, Roman-Roman S, Rueda OM, Seoane J, Serra V, Soucek L, Vanhecke D, Villanueva A, Vinolo E, Bertotti A, Trusolino L (2017) Interrogating open issues in cancer precision medicine with patient-derived xenografts. Nat Rev Cancer 17(4):254-268. 10.1038/ nrc.2016.140 [PubMed: 28104906]

15. Lin RZ, Lee CN, Moreno-Luna R, Neumeyer J, Piekarski B, Zhou P, Moses MA, Sachdev M, Pu WT, Emani S, Melero-Martin JM (2017) Host non-inflammatory neutrophils mediate the engraftment of bioengineered vascular networks. Nat Biomed Eng:1 10.1038/s41551-017-0081

16. Melero-Martin JM, De Obaldia ME, Kang SY, Khan ZA, Yuan L, Oettgen P, Bischoff J (2008) Engineering robust and functional vascular networks in vivo with human adult and cord bloodderived progenitor cells. Circ Res 103 (2):194-202. 10.1161/CIRCRESAHA.108.178590 [PubMed: 18556575]

17. Melero-Martin JM, Khan ZA, Picard A, Wu X, Paruchuri S, Bischoff J (2007) In vivo vasculogenic potential of human blood-derived endothelial progenitor cells. Blood 109 (11):4761-4768 [PubMed: 17327403]

18. Boscolo E, Limaye N, Huang L, Kang KT, Soblet J, Uebelhoer M, Mendola A, Natynki M, Seront E, Dupont S, Hammer J, Legrand C, Brugnara C, Eklund L, Vikkula M, Bischoff J, Boon LM (2015) Rapamycin improves TIE2-mutated venous malformation in murine model and human subjects. J Clin Invest 125(9):3491-3504. 10.1172/JCI76004 [PubMed: 26258417]

19. Goines J, Li X, Cai Y, Mobberley-Schuman P, Metcalf M, Fishman SJ, Adams DM, Hammill AM, Boscolo E (2018) A xenograft model for venous malformation. Angiogenesis 21 (4):725-735. 10.1007/s10456-018-9624-7 [PubMed: 29786783]

20. Li X, Cai Y, Goines J, Pastura P, Brichta L, Lane A, Le Cras TD, Boscolo E (2019) Ponatinib combined with rapamycin causes regression of murine venous malformation. Arterioscler Thromb Vasc Biol 39 (3):496-512. 10.1161/ATVBAHA.118.312315 [PubMed: 30626204]

21. Allen P, Kang KT, Bischoff J (2015) Rapid onset of perfused blood vessels after implantation of ECFCs and MPCs in collagen, PuraMatrix and fibrin provisional matrices. J Tissue Eng Regen Med 9(5):632-636. 10.1002/term.1803 [PubMed: 23955835]

22. Allen P, Melero-Martin J, Bischoff J (2011) Type I collagen, fibrin and PuraMatrix matrices provide permissive environments for human endothelial and mesenchymal progenitor cells to form neovascular networks. J Tissue Eng Regen Med 5(4):e74-e86. 10.1002/term.389 [PubMed: 21413157]

23. Green MR, Sambrook J (2019) Estimation of cell number by hemocytometry counting. Cold Spring Harb Protoc 2019(11):pdb prot097980. 10.1101/pdb.prot097980 


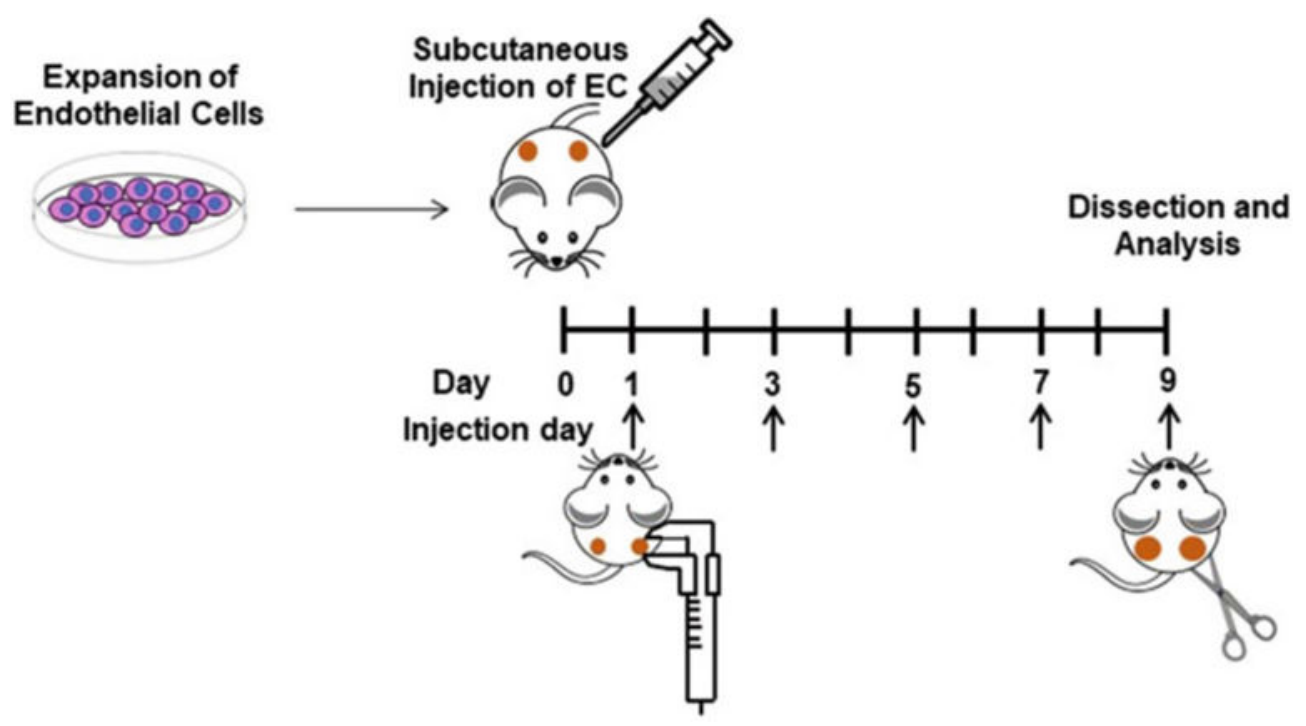

Fig. 1.

Schematic of cell injection in mouse and timeline until dissection. Endothelial cells are expanded to desired number of cells prior to injection day. Subcutaneous injection of EC on day 0 is followed by initial lesion measurement, day 1 . Lesions are measured every other day, as signified by arrows, using a caliper through experimental day 9. Lesions are dissected and processed for tissue analysis on day 9 
a

Back View

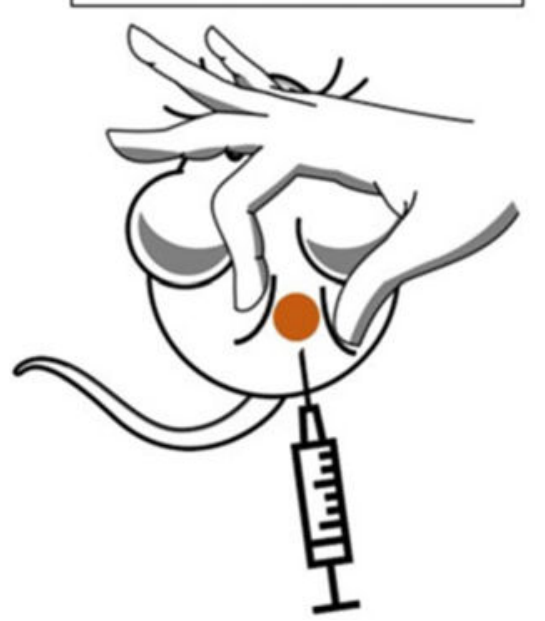

b
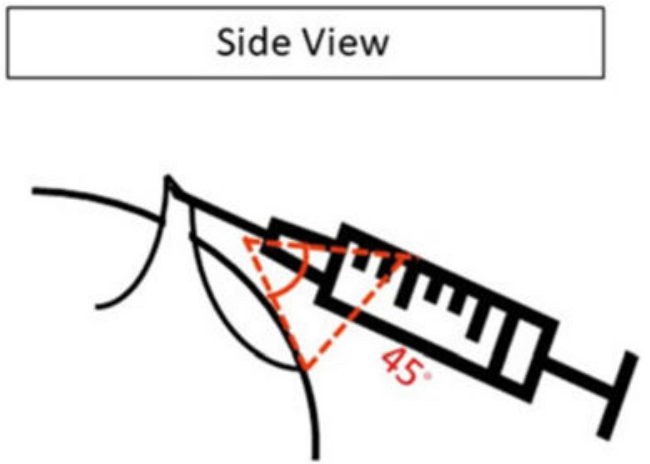

Fig. 2.

Schematic of in vivo injection procedure. Skin on the backside of the mouse is pinched using forefinger and thumb to create a tentlike structure. Next, carefully insert needle into subcutaneous layer and release skin of mouse (a). From the side, there should be a $45^{\circ}$ angle created between the mouse backside and needle when injecting mixture subcutaneously into skin (b) 


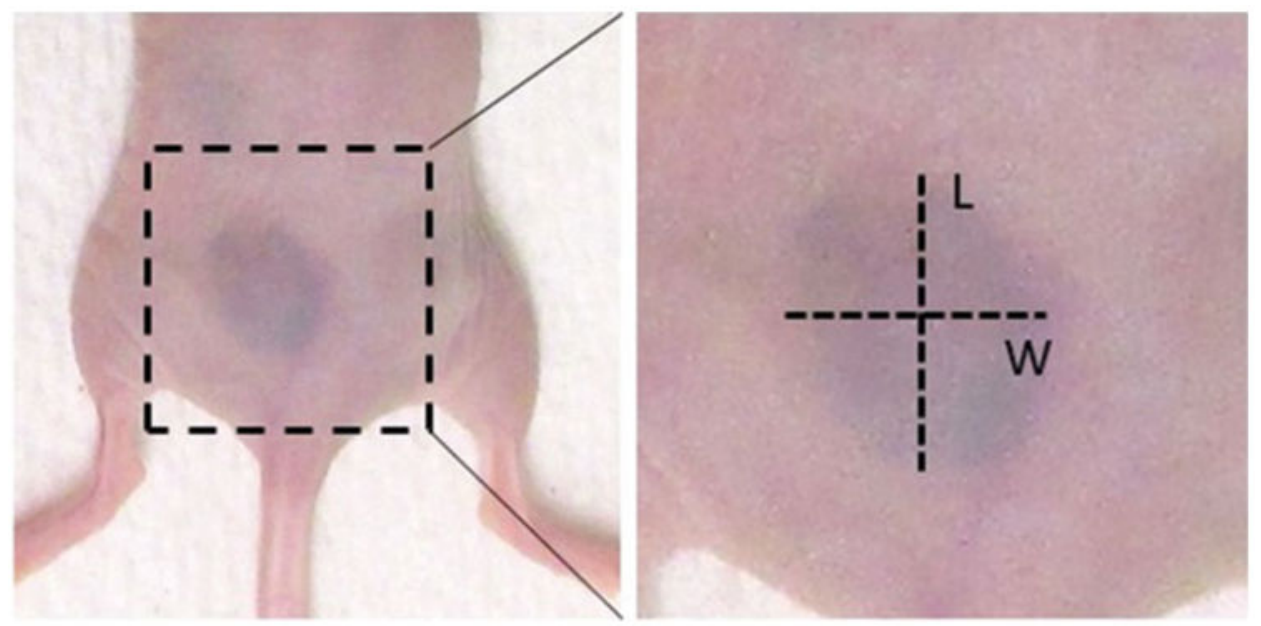

Fig. 3.

Caliper measurement of lesion on mouse. Lesion will form a circular structure on the back. Measure lesion size with a caliper by recording the length (L) and the width (W) 
$H \& E$

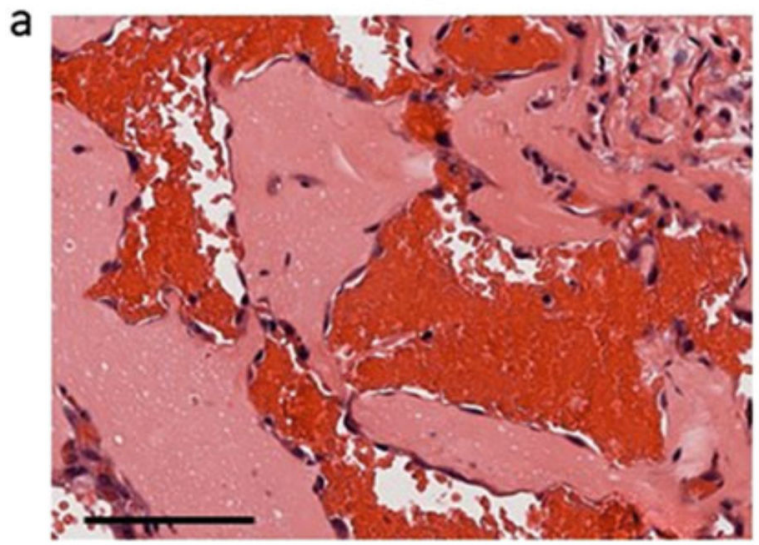

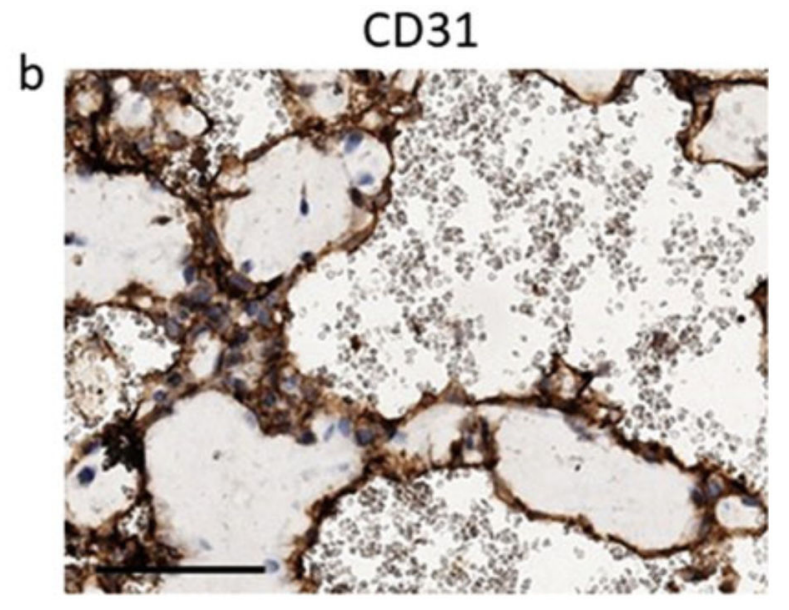

Fig. 4.

Staining of lesion plug with HUVEC-TIE2-L914F. Representative images of lesion plug staining of xenograft model. Hematoxylin and eosin (H\&E), left (a) and immunohistochemistry of endothelial cell marker, anti-human CD31, right (b). Scale bar: $100 \mu \mathrm{m}$ 